\title{
Diagnosis and successful surgical treatment of chronic constrictive uraemic pericarditis
}

\author{
H. R. Jenzer, E. Graedel, and A. Blumberg \\ From the Department of Internal Medicine, Kantonsspital Aarau, and the Division of Cardiovascular Surgery, \\ Department of Surgery, Kantonsspital Basel, Switzerland
}

A case of chronic constrictive uraemic pericarditis successfully treated by pericardectomy is reported together with the pre-and postoperative haemodynamic data.

Uraemic pericarditis has become a common complication of chronic renal failure in patients maintained on haemodialysis. It usually responds to adequate haemodialysis together with pericardiocentesis or the creation of a pericardial window. Sometimes, however, chronic constrictive pericarditis develops, and this is likely to occur more often now that there are so many patients on longterm dialysis. We report here the pre- and postoperative haemodynamic data in such a case-the ninth case, we believe, to be described which has been successfully treated by pericardectomy.

\section{Case report}

In 1967 a 41-year-old man was found to have severe hypertension as a result of chronic renal disease. In 1970 bilateral nephrectomy was performed because of inadequate blood pressure control. The renal histology was that of chronic glomerulonephritis. Maintenance haemodialysis was started in hospital on 5 January 1970; the patient was transferred home on thriceweekly haemodialysis in October 1970. In September 1973 he presented with chest pain, a friction rub, and a much enlarged cardiac silhouette (Fig. 1A). Acute uraemic pericarditis was diagnosed. It was suggested that dialysis should be done in the hospital in order to reduce the amount of anticoagulation needed, but the patient refused. He did not return until 15 January 1974, when he had an infection of the arteriovenous fistula. He stated that his previously moderate exertional dyspnoea had increased since December 1973. Moreover, he had noted that hypotension occurred when he attempted to reduce his weight during ultrafiltration dialysis.

On examination he had obvious neck vein distension, ascites, hepatomegaly (to $7 \mathrm{~cm}$ below the right costal margin), lower extremity oedema, blood pressure of 95 - $120 / 65$ - $90 \mathrm{mmHg}(12.6$ - 16.0/8.7 - $12.0 \mathrm{kPa})$ without paradoxical pulse. Cardiac examination was unremarkable apart from a third heart sound. A chest $x$-ray film (Fig. 1B) showed the cardiac silhouette to be much smaller than it was during the episode of acute pericarditis 3 months before. The electrocardiogram showed ST depression and negative $T$ waves, but no low voltage. In the course of several haemodialyses $7 \mathrm{~kg}$ of the fluid overload was removed, but the patient had a tendency toward hypotension while on dialysis.

The findings on right heart catheterization (see Table) accorded with the clinical diagnosis of chronic constrictive pericarditis. At operation on 19 February 1974 the pericardium was found to be leathery and 1 to $2 \mathrm{~cm}$ thick and the pericardial space was obliterated by fibrous tissue. Successful pericardectomy was performed. The patient's postoperative course was uncomplicated. He was discharged 11 days after the operation. Oedema and ascites gradually disappeared, neck vein distension and hepatomegaly decreased considerably, and heart size increased moderately. Haemodynamic findings confirmed the remarkable improvement (Table). When last seen the patient was continuing to do well.

\section{Discussion}

Uraemic pericarditis is common in patients with renal insufficiency but chronic constrictive uraemic pericarditis is rare. So far as we know, fewer than 20 cases have been reported and only 8 of these have had a successful pericardectomy (Nickey et al., 1971 ; Comty, Cohen, and Shapiro, 1971 ; London et al., 1971; Esmond, Lee, and Hernandez, 1971; Masbernard et al., 1972; Young et al., 1973). However, it is to be expected that, with the increasing use of maintenance haemodialysis, this complication will occur more often.

The diagnosis should be suspected when the following typical features are present. Distended 

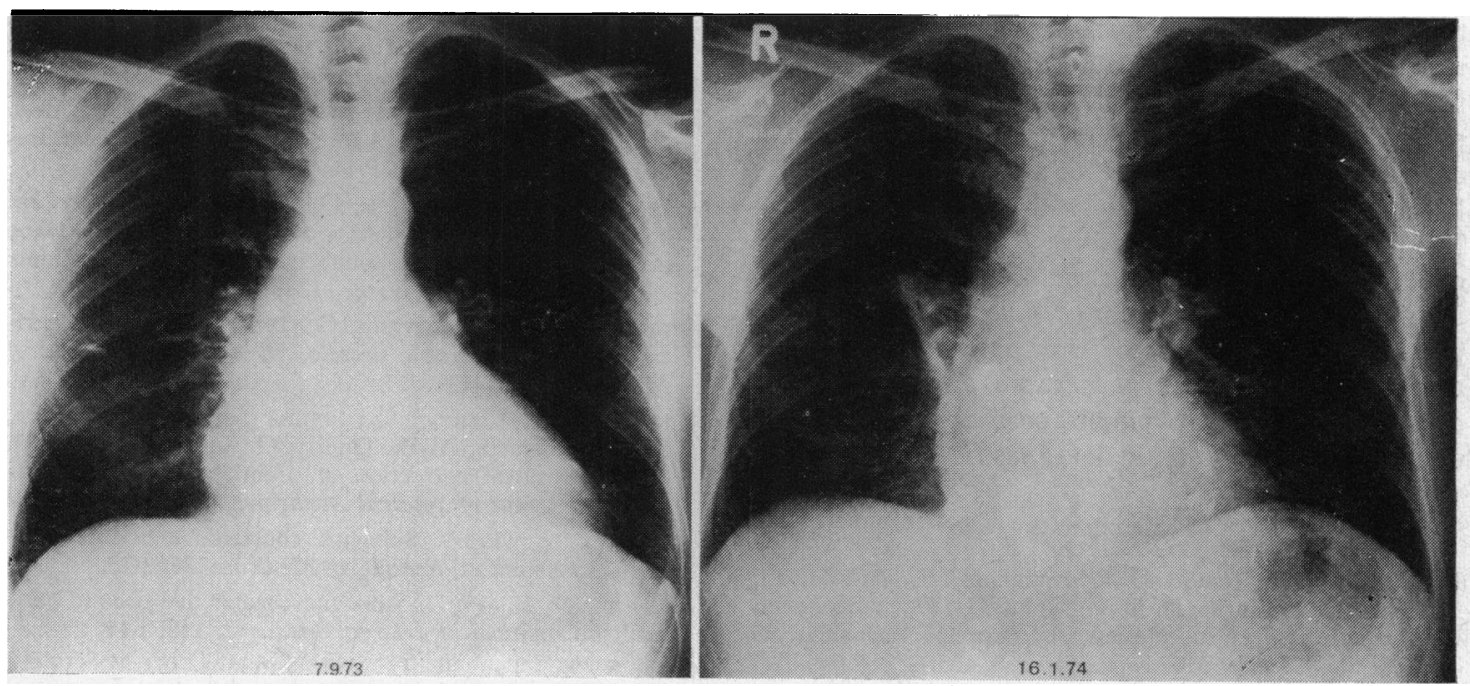

FIG. 1 A) First chest radiograph (7.9.73) made at time of acute uraemic pericarditis shows enlarged cardiac silhouette. B) Second radiograph (16.1.74) shows reduction in heart size.

neck veins, hepatomegaly, ascites, oedema, lowering of a previously raised blood pressure, and decrease in heart size. Cardiac catheterization in our case showed the characteristic haemodynamic changes with a pressure plateau in which the pulmonary wedge pressure, pulmonary artery diastolic pressure, right ventricular end-diastolic pressure, and mean right atrial pressure tended to be equal. An $M$ pattern of the right atrial pressure pulse as well as an early diastolic dip in the right ventricle were also present. These haemodynamic abnormalities and clinical findings are not specific for the disorder, since a similar pressure pattern may be found in restrictive cardiomyopathies.

Chronic constrictive uraemic pericarditis seems to be a sequel to acute uraemic pericarditis. It is not clear why it develops in only a few cases and not in all. Pathogenetically the haemorrhagic nature of uraemic pericarditis is thought to be important. Incomplete resorption and secondary organization will then lead to the characteristic appearance of a spongy granulation tissue with organizing clot and residual fibrin (Reyman, 1969; Esmond et al., 1971) but without calcification. Heparinization during dialysis probably contributes to pericardial bleeding. Therefore so-called regional heparinization should be performed. Unfortunately this was not possible in our case. Usually constriction develops within a few months, as in our patient (Delahaye et al., 1964; Hager, 1965; Spaulding, 1967; Moraski and Bousvaros, 1969;Reyman, 1969; Brogard et al., 1969; Weiss, Taw, and Hutchins, 1973). Only occasionally will it take more than a year (Lindsay, Crawley, and Callaway, 1970; London et al., 1971).

The diagnosis should be evident from the physical findings, the chest $x$-ray examination, and additional right heart catheterization data. Since

TABLE Pre-and postoperative haemodynamic data

\begin{tabular}{lll}
\hline Site & $\begin{array}{l}\text { Pressure } \mathrm{mmHg}(\mathrm{kPa})^{\star} \\
\text { Preoperative }(31.1 .74)\end{array}$ & Postoperative (12.6.74) \\
\hline Right atrium (mean) & $17(2 \cdot 3)$ & $5(0 \cdot 7)$ \\
Right ventricle (systolic/diastolic) & $38 / 20(5 \cdot 1 / 2 \cdot 7)$ & $34 / 10(4 \cdot 5 / 1 \cdot 3)$ \\
Pulmonary artery (systolic/diastolic; and mean) & $42 / 20 ; 27(5 \cdot 6 / 2 \cdot 7 ; 3 \cdot 6)$ & $27 / 9 ; 18(3 \cdot 6 / 1 \cdot 2 ; 2 \cdot 4)$ \\
Pulmonary artery wedge (mean) & $20(2 \cdot 7)$ & $7(0 \cdot 9)$ \\
\hline Cardiac index 1/min per m ${ }^{2}$ (Fick method) & 3.45 & $4 \cdot 8$ \\
\hline
\end{tabular}

*Values in brackets in SI units. 
this form of constrictive pericarditis is usually rapidly fatal prompt diagnosis and operation are mandatory. Without intervention 7 previously reported cases all died within 3 months (Delahaye et al., 1964; Hager, 1965; Spaulding, 1967; Moraski and Bousvaros, 1969; Reyman, 1969; Brogard et al., 1969; Lindsay et al., 1970). Recent experience has shown that major surgery is feasible in patients on maintenance haemodialysis. The postoperative recovery of our patient (as well as that of several others) was rapid and uneventful, and the clinical improvement, corroborated by postoperative haemodynamic data, has been gratifying.

\section{References}

Brogard, J. M., Brandt, C., Kuntzmann, F., Arnold, P., Krivosic, I., Fincker, J. L., and Jahn, H. (1969). Evolution des péricardites urémiques au cours de l'hémodialyse itérative. Coeur et Médecine Interne, 8, 463.

Comty, C. M., Cohen, S. L., and Shapiro, F. L. (1971). Pericarditis in chronic uremia and its sequels. Annals of Internal Medicine, 75, 173.

Delahaye, J. P., Gonin, A., Traeger, J., and Plauchu, G. (1964). Péricardite urémique à évolution constrictive subaiguë. Archives des Maladies du Coeur et des Vaisseaux, 57, 967.

Esmond, W. G., Lee, Y. C., and Hernandez, F. (1971). Successful pericardectomy in chronic constrictive uremic pericarditis. Southern Medical fournal, 64, 533.

Hager, E. B. (1965). Clinical observations on five patients with uremic pericardial tamponade. New England fournal of Medicine, 273, 304.
Lindsay, J., Jr., Crawley, I. S., and Callaway, G. M., Jr. (1970). Chronic constrictive pericarditis following uremic hemopericardium. American Heart fournal, 79, 390.

London, G., Joly, F., Joly, H., Valty, J., Galey, J. J., Man, N. K., Zingraff, J., and Vantelon, J. (1971). Péricardites urémiques constrictives. Presse Médicale, 79, 341.

Masbernard, A., Guilbaud, J., Giudicelli, C., Utzinger, B., and Vallet, M. (1972). Pericardite constrictive chronique urémique, constituée sous hémodialyse périodique. Annales de Médecine Interne, 123, 525.

Moraski, R. E., and Bousvaros, G. (1969). Constrictive pericarditis due to chronic uremia. New England fournal of Medicine, 281, 542.

Nickey, W. A., Chinitz, J. L., Flynn, J. J., Adam, A., Kim, K. E., Schwartz, A. B., Onesti, G., and Swartz, C. D. (1971). Surgical correction of uremic constrictive pericarditis. Annals of Internal Medicine, 75, 227.

Reyman, T. A. (1969). Subacute constrictive uremic pericarditis. American fournal of Medicine, 46, 972.

Spaulding, W. B. (1967). Subacute constrictive uremic pericarditis. Archives of Internal Medicine, 119, 644.

Weiss, S. W., Taw, R. L., and Hutchins, G. M. (1973). Constrictive uremic pericarditis following hemodialysis for acute renal failure. Fohns Hopkins Medical fournal, 132, 301.

Young, M. W., Bupta, M., Hamby, R. I., and Kolker, P. (1973). Hemi-constriction of the heart in uremic pericarditis. Chest, 64, 532.

Requests for reprints to Dr. H. R. Jenzer, Department of Internal Medicine, Kantonsspital, 5000 Aarau, Switzerland. 